\title{
THE IMPLEMENTATION OF SCHOOL-BASED MANAGEMENT FOR SCHOOL EFFECTIVENESS
}

\author{
Nurkolis $^{\mathrm{a}}$ \\ a Program Studi Manajemen Pendidikan, Universitas PGRI Semarang \\ Semarang, Indonesia
}

Corresponding e-mail: nurkolis@upgris.ac.id

\begin{abstract}
School-based Management (SBM) has been implemented in Indonesia since 2000, but after 16 years of implementation there are still many schools that have not succeeded in implementing it. This article aims to measure the impact of SBM implementation on school effectiveness. The objectives are to find out: (a) the impact of SBM implementation to the effectiveness of school management, and (b) the impact of SBM imlementation to the effectiveness of the learning process. The research was conducted descriptively in seven districts namely Semarang, Batang, Pekalongan, Purbalingga, Banjarnegara, Wonosobo, and Sragen in Central Java Province from 2012-2016. Selection of samples of districts was done purposively. The results show that the implementation of SBM has a positive impact on the effectiveness of school management and the effectiveness of the learning process. Based on the results of the study it is suggested that good and successful practices in SBM implementation can be disseminated to other schools and to other districts.
\end{abstract}

Keywords: school-based management, effectiveness of school management, effectiveness of learning process, and school effectiveness

\section{INTRODUCTION}

As the system of government in Indonesia has change from centralized to decentralized, the education system also changes. When the system of governance was centrally managed, the management of education was also done centrally. When the system of governance was decentralized, the management of education was managed in a decentralized way.

A decentralized system of government begins with the issuance of the Law of the Republic of Indonesia No. 22 of 1999 on Regional Government. Since then basic and intermediate education has become obligatory of regional governments either municipalities or provinces. Law No. 22 of 1999 has been changed twice namely Law No. 32 Year 2004 and Law No. 23 Year 2014.

School-based Management (SBM) as a model of decentralized education was first tested in 1999 in several provinces in Indonesia. Funding sources come from governments and grants from several donor countries such as USAID, AUSAID, EU, World Bank, JICA and UNESCO. Until now after more than 16 years implemented and has many success stories as well as the lack of success in this implementation.

The implementation of SBM in Indonesia is officially protected by Law No. 20 of 2003 on National Education System. Chapter IV regulates the management of education, especially article 51 (1) mentioned that the management of early childhood education units, primary education, and secondary education are implemented based on minimum service standards with the principles of school/madrasah based management.

Principles of SBM are regulated in RI Government Regulation No. 19 of 2005 on National Education Standards, Article 49 (1) mentions that the management of educational units at elementary and secondary education levels implements schoolbased management as demonstrated by independence, partnership, participation, openness, and accountability.

One of the donor agencies providing grants for improving basic education in Indonesia was USAID Indonesia through USAID PRIORITAS (Prioritizing Reform, Innovation, and Opportunities for Reaching Indonesias Teachers, Administrators, and Students) programs. This program was implemented in 10 provinces in Indonesia and one of them was in 
Central Java Province which partnered with 7 (seven) selected districts namely Semarang, Batang, Pekalongan, Purbalingga, Banjarnegara, Wonosobo, and Sragen since 2012-2017. This program was a technical assistance in the form of training and community empowerment in managing quality basic education.

Similar programs in some places have mixed results, some have improved school management and learning processes [1]. But there are those who have not succeeded in improving the quality of education [2]. Form of participation was still in the form of physical, not yet to the thinking as in decision making [3]. Decentralization of education in Indonesia using the SBM model was predicted to manage autonomous education programs and educational financial accountability [4].

Many challenges are faced in the implementation of SBM starting from the pessimism of education stakeholders on the impact on improving the quality of education to the coherence of cooperation with the local government. Research on the implementation of SBM in Ngada Flores [5] found several problems such as lack of professionalism development of principals, lack of facilities, lack of knowledge about SBM, and lack of funding.

Therefore this study intends to answer two main questions: (a) does the implementation of SBM have an impact on the effectiveness of school management, and (b) does the implementation of SBM have an impact on the effectiveness of the learning process?

\section{METHOD}

The research was conducted in seven districts in Central Java Province namely Semarang, Batang, Pekalongan, Purbalingga, Banjarnegara, Wonosobo, and Sragen. The selection of districts was done purposively based on USAID PRIORITAS program. Evaluation were made four times at the beginning of the program (2012), the end of year 2 (2013), the end of year 4 (2015), and the 5th year (2016). The evaluation team consisted of teachers, principals, school supervisors, staff of the education office, students of university, and lecturers. Data collection was done with interview, observation, and documentation. Data analysis with percentage and Pearson correlation. Results were compared between partner schools and comparison schools for elementary and junior high schools of SMP-MTs. The number of schools studied was 64 schools consisting of partner schools and comparison schools. Partner schools are schools that receive continuous treament during the program. Treatment was on the form of training and coaching by trained facilitators. Meanwhile, the comparison schools did not get treatment directly, but get the impact or imitate from partner schools.

\section{RESULT AND DISCUSSION}

In Indonesia, the implementation of SBM was expected to be able to improve the school's effectiveness which is none other than the increased quality of schools. School effectiveness is a quality school that can be reviewed from the aspect of the quality of school management and apsek the quality of the learning process. Therefore the results and discussion in this article are focused on those two aspects.

\subsection{Does SBM have a positive impact on the effectiveness of school management?}

School management indicators in this study are demonstrated by the principal's leadership in initiating educational leadership, developing school activities and budgets, community participation in improving the learning process, and initiating of principals to develop a reading culture in schools.

The following is a measurement of the progress of school management in partner schools.

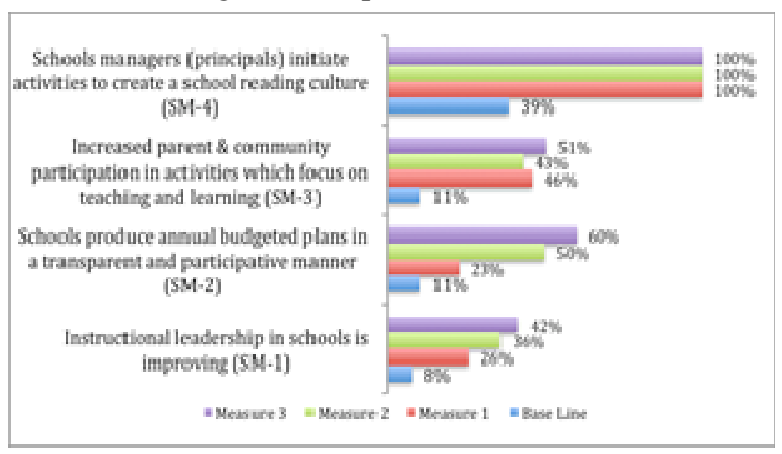

Figure 1. School Management Performance at Partner School

The effect of SBM implementation on the improvement of school management based on the base line result compare to the final measurement of the program was 0.78 which means the effect is very strong. Meanwhile, the level of determination reached $60 \%$. This means that the improvement of school management was influenced by the SBM program in the form of training and mentoring at the school level, while $40 \%$ is influenced by other factors.

Extraordinary and highly conducive progress 
over the last four years was the principal's initiative to develop a reading culture in schools, whose scores reach $100 \%$. This is because along with the government program that campaigns reading culture as one of the realization of character education.

Measurements were also made to the comparison schools, the schools did not get treated like partner schools but were impacted by imitating and getting transmitted from partner schools. The results of measurements at comparative schools are inconsistent from year to year, as shown in Figure 2.

Here are the measurements of the progress of school management in comparison schools.

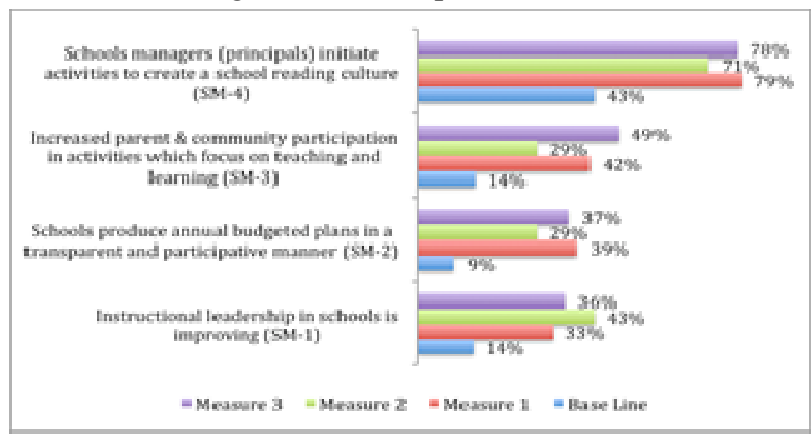

Figure 2. School Management Achievement in Comparative School.

This research supports the results of research conducted in Minahasa [1] that the implementation of SBM has a positive impact on improving school management: schools are more transparent, participatory, democratic, and accountable, and increase community participation in education. In addition, the implementation of SBM in Minahasa conducted since 2007 and evaluated in 2013 has a positive impact on the quality of education including lowering the drop out rate and making learning more active, creative, effective, and fun.

This finding is slightly different from the results of the study in Aceh Utara District [2], that from the analysis of the 20 items of the school committee's response to the implementation of SBM was still very low, only $65 \%$ can support the improvement of education quality. Program increased was on cooperation with parents to improve the assistance on teaching and learning.

In Ethiopia, the implementation of SBM also still faces obstacles, especially in community participation. Participation was still more in the contribution of money than the contribution of thought like in the decision making process [3]. Women in rural areas were also difficult to participate in advancing education. Under these conditions it was recommended that the government should make a clear policy. Likewise, the poor have difficulty in participating due to their lack of time, experience, and resources [6].

The lack of clarity in SBM implementation policy will be an obstacle in the implementation. This has been experienced by Indonesia during the implementation of SBM in the early stages. Unclear government regulations or ministerial regulations because they are not accompanied by clear technical guidelines was a constraint on the implementation of SBM at the time [5].

The positive impact of SBM implementation on the quality of education was also found in other studies [7]. Schools that have implemented SBM have been able to make correct decisions on allocating the use of educational resources, appoint non-civilian teachers, create a learning environment that supports the learning process, and increase teacher attendance in the classroom. Finally, SBM implementation can improve student learning outcomes [8].

\subsection{Does SBM have a positive impact on the effectiveness of the learning process?}

Indicators of the learning process in this study are teachers using regular reading material, teachers show good learning practices (make preparation of teaching and implement learning actively), teachers support and develop students' reading ability, students show positive learning attitude (active participation in answer, ask questions, make assignments, and search for learning resources). Such learning processes show an effective learning process.

Schools that receive SBM program assistance can improve consistently on aspects of the quality learning process. The most prominent changes associated with students demonstrate positive learning behaviors (TL-3). At the time of initial measurement before the SBM program was run the students who showed positive behavior only $18 \%$. The students tend to be passive in the learning process and the more active is the teacher (teacher centered). The large increase starts from the 2 nd measurement that reaches $90 \%$, the $3 \mathrm{rd}$ measurement reaches $95 \%$, and the last measurement reaches $100 \%$.

The following is the measurement of the progress of the learning process in partner schools.

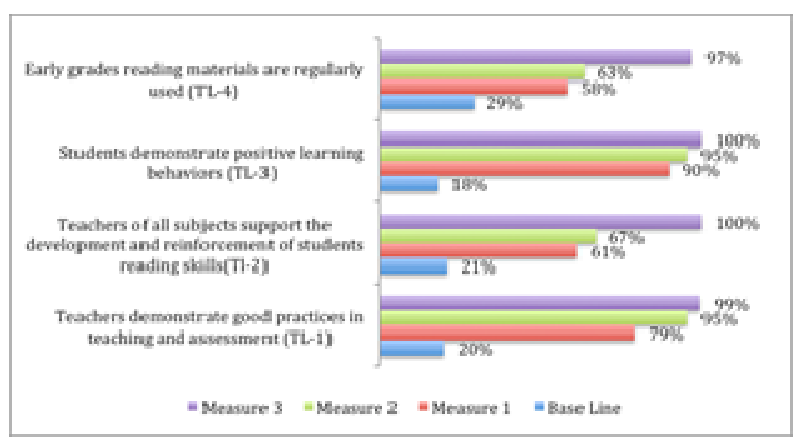


Figure 3. Outcomes of the Learning Process at Partner School

In comparison schools, there was also a significant increase in learning process. This is because the success of partner schools in implementing SBM quickly spread to the impact school that became a comparison school. The District Education Office ordered that the schools of impact go to partner schools. Facilitators from partner schools are also asked to train comparison schools in terms of learning. Therefore, starting from the second year the comparison schools are also trained by the same facilitator with the budget from the Local Government or independent from their respective schools.

The best achievement in comparison schools was in the learning aspect on the 3rd indicator of "studens demonstrate possitive learning behaviors" (TL-3), based on the latest measurement results reaching $78 \%$. This is consistent with the same aspects and indicators in partner schools that achieve the highest achievement.

Here are the measurements of the progress of the learning process in comparison schools.

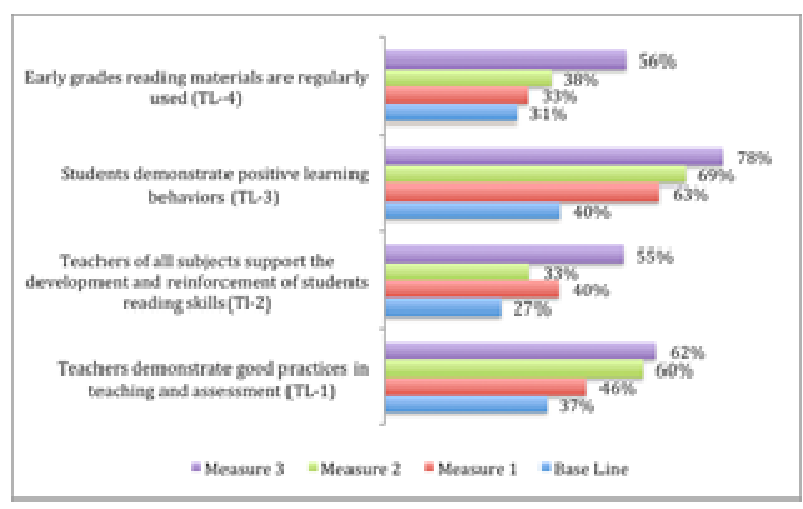

Figure 4. Achievement of Learning Process at Comparative School

Based on base line measurements at partner schools, the average school quality for school management and learning process was only $19 \%$ or very poor, while in comparison schools it has reached $28 \%$ or worse. However, based on the last measurement, the average quality of school in partner schools reached $81 \%$ or good while the comparison school only $65 \%$ or enough. This means that there is a significant difference between intensively treated schools and schools that are not getting intensive treatment.

The progress of school quality from each indicator in the school management component and the learning process at partner schools and comparison schools can be seen in the following figure.

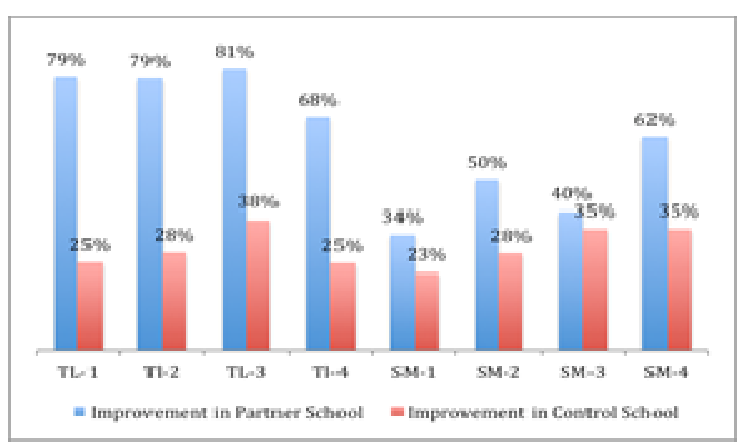

Figure 5. Differences from Measurements 1st and 4th in Partner School and Comparative School

In the school management aspect, the lowest indicator of improvement in both partner schools and comparative schools was SM-1 namely 'instructional leadership in schools is improving', because in this program there is no special activity to improve the principal's competence in instructional leadership.

Community participation indicators (SM-3) in schools also increased, but not so greatly improved. In partner schools increased by $40 \%$ and in comparison schools increased 35\%. Teachers and principals in partner schools acknowledge that it was still difficult to mobilize the community to think about school progress. This seems to be a common phenomenon in undeveloped countries. In Ethiopia also found problems like this [3]. In Indonesia, what is considered to be school parsitipation was participation in school funding. While participation in thought related to the process of learning is still low.

In Ngada Flores [5] indicates that the implementation of SBM by mandating the school committee has increased community participation in decision-making and school co-operation with the community. The quality of decision-making also increased, that $82 \%$ of school committees acknowledged that decision-making was done through agreement. In Queensland the implementation of SBM also enhances community participation in education [6].

In the aspect of school management, indicator of participative school-planning and transparent budgetinf (SM-2) has shown substantial improvement. This is because one of the focuses of training and assistance in this program was the strengthening of school work plan and school finance plan. Each school gets at least 3 days training and mentoring at least 10 times. In partner schools there was an increase of $50 \%$, whereas only 
$11 \%$ of comparison schools made school plans and activities in a transparent and participatory way.

In order for schools to become more transparent there must always be pressure from various parties. As reported in one of the following research results. "We find that the pressure of some groups of stakeholders improves the quality of transparency of the reports. Our results show that transparency is affected by ownership, along with size and global region [10].

In the aspect of the process of learning, the lowest progress was obtained in the 4th indicator of "early grades reading materials are regularly used" (TL-4). In partner schools progress has reached $68 \%$, but in comparison schools only reached $25 \%$. The low increase in this indicator was related to the availability of funds. Based on principals and teachers' remarks that school finance is currently only obtained from BOS (School Operational Assistance). Allocation of funds from BOS has been determined by the central government. The purchase of books outside the textbook is very limited in budget.

The first indicator is "teachers demonstrate good practices in teaching and assessment" (TL-1) and the second is "teachers of all subjects support the development and reinforcement of students reading skills" (TL-2) in partner schools an equal increase of $79 \%$. This is very logical because the main focus of this program was the improvement of teacher competence in teaching. Each partner school was trained for a minimum of 5 days with assistance at least 20 times.

\section{CONCLUSIONS}

Implementation of SBM has a positive impact on school effectiveness or school quality improvement, related to the quality of school management and the quality of the learning process. It is suggested that good and successful practices in SBM implementation can be disseminated to other schools and to other districts.

Based on the progress of each indicator and based on the results of research in other countries there needs to be various improvements, especially related to government regulations and policies.

First, learning from the experiences of countries in Central America (such as El Safador, Guatemala, and Nicaragua) in the implementation of SBM, there is currently a tendency to stop the implementation of SBM [11]. SBM reforms in Central American countries have started since the 1990s. Based on the analysis of research results there then it is necessary to stipulate the scope of educational reform through the SBM model more specifically in order not too widespread. In addition, for successful implementation of SBM then the government needs to invest the budget seriously.

Secondly, we also need to learn from the weakness of SBM implementation from Iran one of them was related to school financing policy. The central government was expected to make school finance policies, while local governments and schools allocate resources that are in the region and at school level [12].

Third, one of the weaknesses of SBM implementation in Indonesia was the lack of trust between the government and local governments to schools. So one of the suggestions given in Indonesia is that there must be trust in the school other than empowering stakholder in school [13].

Fourth, therefore, there needs to be a clear policy related to the strengthening of school citizens. It is necessary to clarify what matters are the school autonomy and the desired level of school accountability. It is also necessary to have a support system supplied in the principal's selection [14].

\section{ACKNOWLEDGEMENTS}

Our thanks go to the USAID PRIORITAS Team of Central Java Province who has facilitated the collection of data in this study. USAID PRIORITAS was a program of educational empowerment in Indonesia resulted from the cooperation between the Government of Indonesia and the US Government implemented in 2012-2017.

\section{REFERENCES}

[1] Rawung, F. The Implementation of SchoolBased Management to Alleviate the Quality of Education in High Schools and Vocational Schools in Minahasa Regency. International Journal of Humanities and Social Science Invention, 4(7), 53-64. 2015.

[2] Jalaludin; Azwir, \& Akmal, N. Implementation of School-Based Management at SMA on District of North Aceh. Researchers World, 6(4), 35. 2015.

[3] Swift-Morgan, J. What Community Participation in Schooling Means: Insights from Southern Ethiopia. Harvard Educational Review, 76(3), 339-368. 2006. https://doi.org/10.17763/haer.76.3.e475j32j69q $27 \times 63$.

[4] Firman, H., \& Tola, B. The Future of Schooling in Indonesia. Journal of International Cooperation in Education, 11(1), 71-84. 2008.

[5] Bandur, A. School-based management developments and partnership: Evidence from 
Indonesia. International Journal of Educational Development, 32(2), 316-328. 2012.

https://doi.org/10.1016/j.ijedudev.2011.05.007.

[6] Cranston, N. C. Collaborative decision-making and school-based management: Challenges, rhetoric and reality. Journal of Educational Enquiry, 2(2), 1-24. 2001.

[7] Abadzi, H. School-based management committees in low-income countries: Can they improve service delivery? Prospects, 43(2), 115-132.

2013. https://doi.org/10.1007/s11125-013-9267-9.

[8] Sumintono, B. School-Based Management Policy and Its Practices at District Level in the Post New order Indonesia. Journal of Indonesian Social Sciences Humanities, 2 (May 1998), 41-67. 2009.

[9] Chen, D. School-based management, school decision-making and education outcomes in Indonesian primary schools. World Bank Policy Research Working Paper Series. 2011.

[10] Fernandez-Feijoo, B., Romero, S., \& Ruiz, S. Effect of Stakeholders' Pressure on Transparency of Sustainability Reports within the GRI Framework. Journal of Business Ethics, 122(1), 53-63. 2014. https://doi.org/10.1007/s10551-013-1748-5

[11] Ganimian, A. J. Why do some school-based management reforms survive while others are reversed? The cases of Honduras and Guatemala. International Journal of Educational Development, 47, 33-46. 2016. https://doi.org/10.1016/j.ijedudev.2015.12.001.

[12] Moradi, S., Hussin, S. Bin, \& Barzegar, N. School-Based Management (SBM), Opportunity or Threat (Education systems of Iran). Procedia - Social and Behavioral Sciences, 69 (Iceepsy), 2143-2150. 2012. https://doi.org/10.1016/j.sbspro.2012.12.179.

[13] Hadijaya, Y. School Based Management at Matauli 1 State Senior High School Pandan. Researchers World, 6(4), 55. 2015.

[14] Grauwe, a De. School-based management ( SBM ): does it improve quality? Quality, 1-14. 2005. 